\title{
Brown adipose tissue genes in pericardial adipose tissue of newborn sheep are downregulated by maternal nutrient restriction in late gestation
}

\author{
Shalini Ojha', Lindsay Robinson', Momina Yazdani', Michael E. Symonds' and Helen Budge ${ }^{1}$
}

BACKGROUND: Brown adipose tissue (BAT) thermogenesis is essential for newborn survival. Pericardial adipose tissue is a visceral depot that promotes metabolic and cardiovascular adaptations. We determined whether BAT is present in pericardial adipose tissue in newborns and whether maternal nutrition during late gestation compromises BAT in the postnatal period.

METHODS: We measured uncoupling protein 1 (UCP1) and other BAT-specific genes (e.g., $\beta 3$-adrenergic receptor ( $\beta 3 A D R$ ) and deiodinase type $2(\mathrm{DIO} 2)$ ), together with markers of white adipose tissue (WAT) in sheep on either the first or 30th day after birth. These were twin offspring born to mothers fed with either $100 \%$ or nutrient restricted (NR) to $60 \%$ of their total metabolizable requirements from $110 \mathrm{~d}$ gestation to term.

RESULTS: Gene expression of UCP1 and other BAT-related genes decreased significantly with age. In newborns, maternal nutrient restriction downregulated gene expression of $\mathrm{DIO} 2$ and the $\beta 3$-adrenergic receptor with reduced UCP1 but had no effect on genes predominantly expressed in WAT.

CONCLUSION: BAT is present around the heart in newborns. Exposure to a suboptimal maternal diet in late gestation specifically compromises BAT development and has the potential to place these offspring at increased risk of hypothermia after birth without effects on the subsequent appearance of WAT.

B rown adipose tissue (BAT) has a unique role in energy homeostasis because it can produce up to $300 \mathrm{~W} / \mathrm{kg}$ of heat by adaptive thermogenesis (1). This provides a potential compensatory mechanism against excess weight gain via coldor diet-induced adaptive thermogenesis (2). In the newborn, BAT is essential for thermoregulation, and its function is critical for survival. In the fetus, BAT development is dependent on several endocrine factors including thyroid hormones, catecholamines, cortisol, and prolactin (3).

Uncoupling protein (UCP)1, a $32-\mathrm{kDa}$ protein in the inner mitochondrial membrane and exclusively found in BAT, appears in the fetus around midgestation (4), and thereafter its expression in perirenal adipose tissue increases up to term before rapidly declining so that it is undetectable by the end of the first month after birth (5). Gene expression of UCP1 is nutritionally regulated, at least in part, and is downregulated in response to late-gestation maternal nutrient restriction (6). The abundance of the UCP1 is also affected by maternal nutrition with raised abundance in the near-term fetus with increasing maternal food intake (7) but no demonstrable change in response to late-gestation maternal nutrient restriction (6). In the fetus and newborn, regulation of mitochondrial membrane proteins such as voltage-dependent anion channel (VDAC) and cytochrome $c$, which are important for energy metabolism within adipocytes, also occurs in response to maternal nutritional perturbations $(3,8)$. BAT differs from white adipose tissue (WAT) in its expression of several other genes, and microarray analysis followed by verification by real-time PCR has demonstrated that expression of transglutaminase 2 (TGM2) and potassium channel, subfamily K, member 3 (KCNK3), are almost fourfold higher in human BAT than in WAT (9).

The process of nonshivering thermogenesis and the proliferation, differentiation, and apoptosis of brown adipocytes are regulated by sympathetic innervation by $\beta 3$ adrenergic receptors ( $\beta 3 A D R)(10)$. Norepinephrine, via $\beta 3 A D R$, increases intracellular cAMP concentrations, which in turn activate hormone-sensitive lipase. This increases lipolysis and the availability of free fatty acids for thermogenesis (10). Prolonged norepinephrine action increases mitochondrial numbers in brown adipocytes (11). In addition, $\beta 3$ ADR stimulates the conversion of thyroxine (T4) into 3,5, $3^{\prime}$-triiodothyronine (T3) by activating type 2 iodothyronine deiodinase (DIO2). The thermogenic function of BAT, particularly on cold exposure, requires high T3 concentrations that are maintained by DIO2 action (12).

The presence of BAT around the hearts of human adults has been confirmed by the presence of BAT-specific UCP1 in epicardial fat (13). Cardiac natriuretic peptides can activate the expression of UCP1 and the transcription coregulator PGC1 $\alpha$ expression and induce mitochondriogenesis in adipocytes (14). Brown adipocytes can also act as lipid-clearing organs with the potential to act as buffers that shield the heart from hypertriglyceridemia (15). Therefore, it has been postulated that the presence of BAT in the vicinity of the heart may protect this 
vital organ from hypothermia and metabolic stresses (10). In the newborn sheep, pericardial adipose tissue constitutes up to $20 \%$ of total BAT, although its exact role around the heart is unclear and there are no studies on this depot in newborns or of its development in the postnatal period.

The aim of this study was, therefore, to investigate the presence of BAT in pericardial adipose tissue of neonatal sheep. Given that maternal nutrient restriction can affect BAT development in the fetus (6), we hypothesized that BAT is present in pericardial adipose depots and that maternal nutrient restriction during late gestation, coincident with maximal growth of the fetus, would compromise the abundance and development of BAT in the newborn over the first month of life.

\section{RESULTS}

Whole Body, Heart, and Adipose Tissue Weights and Adipose Tissue Composition

There was a significant increase in total body weight, heart weight, and the absolute and relative pericardial adipose tissue weights between days 0 and 30 . However, there was no difference between offspring of control and nutrient-restricted (NR) mothers at either age (Table 1). A significant reduction in total protein and mitochondrial protein content occurred between days 0 and 30, but there was no effect of maternal diet in late gestation at either age.

\section{Mitochondrial Proteins in the Newborn and Effect of Maternal Nutrient Restriction}

The protein abundances of both UCP1 and cytochrome $c$ were significantly reduced in offspring born to NR mothers at day 0 , but not day 30, as the abundance of both these proteins declined with postnatal age to basal values irrespective of maternal diet in pregnancy (Figure 1). By contrast, the abundance of VDAC was unaffected by either postnatal age or maternal diet (control, day 0: $1.00 \pm 0.10$; control, day 30: $0.90 \pm 0.10$; NR, day 0: $0.93 \pm 0.10 ; \mathrm{NR}$, day 30: 0.92 \pm 0.05$)$.

\section{Effect of Maternal Nutrient Restriction on BAT-Related Genes}

Gene expression of UCP1 declined with age but was unaffected by maternal diet (Figure 1). TGM2 and KCNK3 mRNA expression was significantly reduced in offspring born to NR mothers on day 0 and was further reduced with age, irrespective of maternal diet (Figure 2). Gene expression for the prolactin receptor and the transcription factor PGC1 $\alpha$ decreased

Table 1. Mean total body weight, pericardial adipose tissue and heart weights, and total protein and total mitochondrial protein contents of pericardial adipose tissue (relative to protein content of control group) in offspring of control and nutrient-restricted mothers at day 0 and day 30 of life

\begin{tabular}{|c|c|c|c|c|}
\hline & $\mathrm{CO}(n=7)$ & $\mathrm{NRO}(n=7)$ & $\mathrm{C} 30(n=8)$ & $\operatorname{NR30}(n=9)$ \\
\hline Body weight (kg) & $4.46 \pm 0.34^{a}$ & $4.26 \pm 0.16^{b}$ & $15.59 \pm 0.77^{c}$ & $14.84 \pm 0.55^{d}$ \\
\hline Total pericardial adipose tissue weight (g) & $4.61 \pm 0.43^{e}$ & $4.01 \pm 0.33^{f}$ & $97.28 \pm 11.93^{9}$ & $98.56 \pm 3.17^{\mathrm{h}}$ \\
\hline Heart weight (g) & $33.37 \pm 2.16$ & $30.60 \pm 1.06$ & $62.88 \pm 1.19$ & $60.69 \pm 2.09$ \\
\hline
\end{tabular}

Pericardial adipose tissue was sampled from 6-h-old (0) and 30-d-old (30) lambs born to sheep that consumed either 100\% (control) or 60\% (NR) of total metabolizable energy

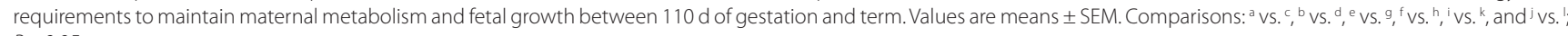
$P<0.05$.
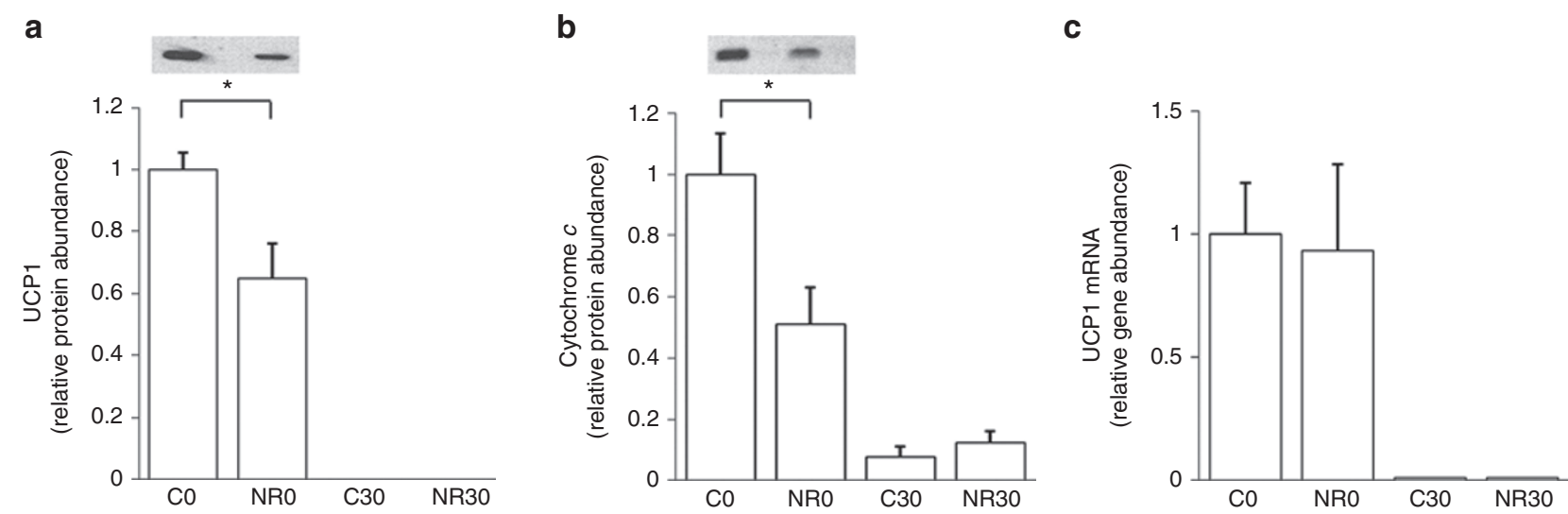

Figure 1. Effects of maternal nutrient restriction on BAT-related genes in the newborn (a) UCP1 protein abundance, (b) cytochrome $c$ protein abundance, and (c) UCP1 mRNA expression in pericardial adipose tissue of sheep in early postnatal life and the effect of maternal nutrient restriction in late gestation. Pericardial adipose tissue was sampled from 6-hr old (0) and 30-d-old (30) lambs born to sheep that consumed either 100\% (control) or 60\% (NR) of total metabolizable energy requirements to maintain maternal metabolism and fetal growth between $110 \mathrm{~d}$ of gestation and term. Values are means \pm SEM; $n=7-9$ per group. ${ }^{*} P<0.05$. NR, nutrient restricted. 

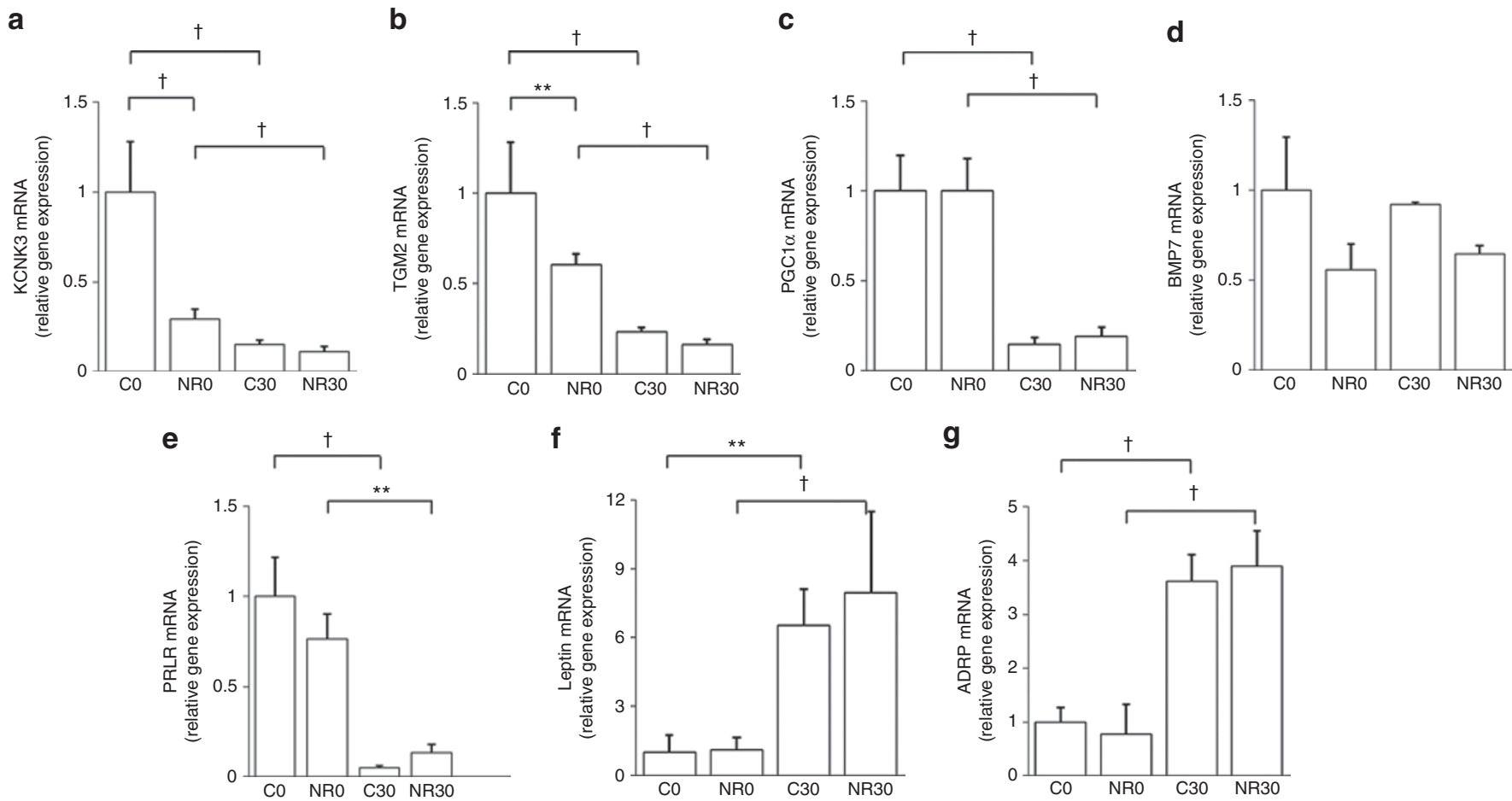

Figure 2. Gene expression of (a) KCNK3, (b) TGM2, (c) PGC1 $\alpha$, (d) BMP7, (e) prolactin receptor, (f) leptin, and (g) ADRP in pericardial adipose tissue of sheep in early postnatal life and the effect of maternal nutrient restriction in late gestation. Pericardial adipose tissue was sampled from 6-h-old (0) and 30 - $\mathrm{d}$-old (30) lambs born to sheep that consumed either $100 \%$ (control) or $60 \%$ (NR) of total metabolizable energy requirements to maintain maternal metabolism and fetal growth between $110 \mathrm{~d}$ of gestation and term. Values are means $\pm \mathrm{SEM} ; n=7-9$ per group. ${ }^{* *} P<0.01,{ }^{+} P<0.001$. NR, nutrient restricted.
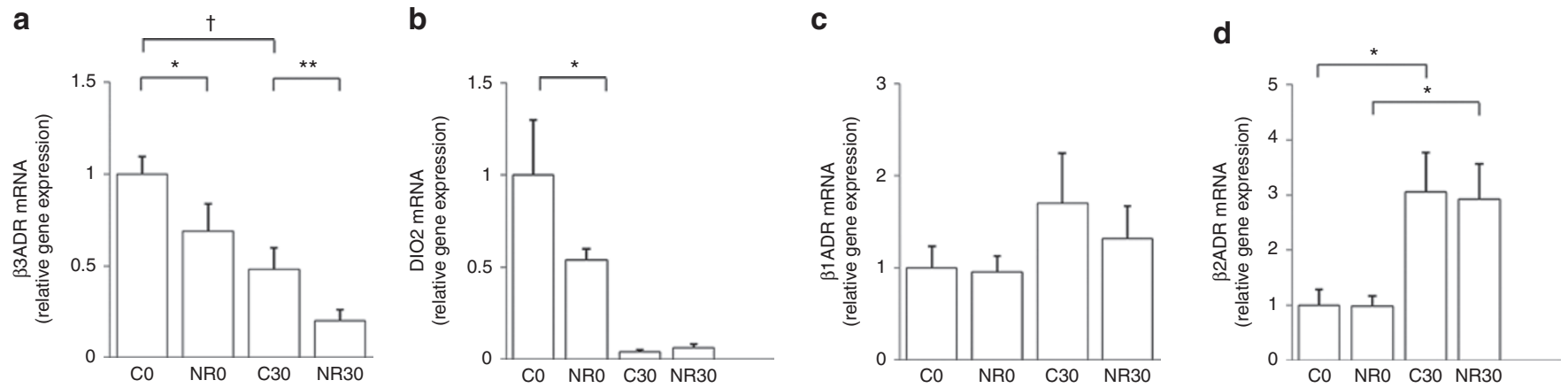

Figure 3. Gene expression of (a) $\beta 3$ adrenergic receptors, (b) type 2 iodothyronine deiodinase, (c) $\beta 1$ adrenergic receptors, and (d) $\beta 2$ adrenergic receptors in pericardial adipose tissue of sheep in early postnatal life and the effect of maternal nutrient restriction in late gestation. Pericardial adipose tissue was sampled from 6-h-old (0) and 30-d-old (30) lambs born to sheep that consumed either $100 \%$ (control) or $60 \%$ (NR) of total metabolizable energy requirements to maintain maternal metabolism and fetal growth between $110 \mathrm{~d}$ of gestation and term. Values are means $\pm S E M ; n=7-9$ per group. ${ }^{*} P<$ $0.05,{ }^{* *} P<0.01,{ }^{\dagger} P<0.001$. NR, nutrient restricted.

with age but was also unaffected by maternal diet. There was no change in the expression of bone morphogenetic protein (BMP) 7, whereas the mRNA expression of WAT-related genes leptin and adipose differentiation-related protein significantly increased between days 0 and 30 in both groups.

\section{Expression of Genes Controlling Nonshivering Thermogenesis} The gene expression of $\beta 3 \mathrm{ADR}$ decreased significantly between days 0 and 30 and was significantly reduced in offspring born to NR mothers at both ages. DIO2 expression decreased with age and was significantly downregulated in offspring of NR mothers at day 0 (Figure 3 ). Gene expression for the $\beta 1$ adrenergic receptor $(\beta 1 \mathrm{ADR})$ was unaffected with age, whereas that of the $\beta 2$ adrenergic receptor ( $\beta 2 A D R$ ) increased with age but was unaffected by maternal diet.

\section{DISCUSSION}

We have shown, for the first time, that BAT is present in pericardial adipose tissue in postnatal sheep as determined by the presence of mRNA and protein for the BAT-specific UCP1. Similar to other depots such as perirenal adipose tissue (5), there is a loss of UCP1 mRNA and protein, decreased 


\section{Articles | ojhaetal.}

expression of BAT-related genes, and increased expression of WAT-related genes in pericardial adipose tissue suggesting that, from birth to $30 \mathrm{~d}$, pericardial adipose tissue turns from predominantly brown to a white adipose tissue depot.

The other major finding of our study is that BAT development is modulated by maternal nutrient restriction in late gestation. Reduced UCP1 abundance is accompanied by a decline in cytochrome $c$ but not in VDAC, which has a role in ADP transport, and changes in its expression produce tissue-specific effects (16). BAT has a high concentration of cytochrome $c$, a protein in the inner mitochondrial membrane, which is part of the electron transport chain, and the cytochrome $c$ content of BAT correlates with the high oxygen consumption in this tissue. In perirenal adipose tissue and the lung, VDAC and cytochrome $c$ are upregulated by maternal nutrient restriction (8) and these current findings represent depot-specific responses to alterations of the in utero environment.

Importantly, we have also demonstrated that maternal nutrient restriction in late gestation downregulates genes that control nonshivering thermogenesis, although this remains to be confirmed in vivo. Offspring of NR mothers have reduced expression of $\beta 3 \mathrm{ADR}$ at birth and $1 \mathrm{mo}$ of age, whereas gene expression of DIO2 is significantly reduced in the newborn. The $\beta 3 A D R$ receptor promotes proliferation and differentiation of brown adipocytes, inhibits apoptosis, and controls the process of nonshivering thermogenesis by upregulating fatty acid oxidation and activating DIO2 (17). The enzyme DIO2 is essential for optimal thermogenesis in brown adipocytes (12), and in its absence in mice, basal UCP1 mRNA expression does not change, but the animals fail to increase their temperature on norepinephrine infusion when there is a $50 \%$ reduction in UCP1 expression (18). High local concentrations of T3 are essential for mitochondrial biogenesis (19) and UCP1 gene expression and lipolysis are impaired in its absence (18). In our study, DIO2 and $\beta 3 A D R$ were downregulated with maternal nutrient restriction in late gestation. These may be mechanisms that make the newborn less capable of modulating body temperature when challenged with cold stress, making the offspring of NR more susceptible to hypothermia.

TGM2 and KCNK3, two genes known to have fourfold higher expression in BAT than in WAT in humans (9), are highly expressed in sheep and their mRNA expression declines by $30 \mathrm{~d}$ of age, parallel to the decline in UCP1. The transcription regulators of the PGC1 family control many aspects of mitochondrial biology (20) and are essential for BAT thermogenesis. In the present study, the ontogeny of PGC1 $\alpha$ in pericardial adipose tissue parallels that of UCP1. However, gene expression of another transcription factor, BMP7, which regulates the differentiation of preadipocytes into mature BAT cells, does not change over the first $30 \mathrm{~d}$ after birth. This suggests that, although brown adipocytes disappear, preadipocytes retain the potential to develop into brown adipocytes, a proposal supported by the discovery of BAT in human adults (21) and the isolation of progenitor cells from human adult supraclavicular adipose tissue, which can develop into mature brown adipocytes (22).
Data from the Dutch "Hunger Winter" (the Famine of 1944-1945) have shown that the timing of maternal nutrient restriction impacts metabolic outcomes in the offspring (23). In guinea pigs, maternal undernutrition increases the relative adiposity of the fetus and appears to preserve WAT at the expense of BAT in the interscapular depots (24). In sheep, maternal nutrient restriction in late gestation results in a 2.5fold decrease in the abundance of UCP1 mRNA in near-term fetal adipose tissue, but there is no effect on protein abundance at this stage (6). On the other hand, longer periods of nutrient restriction, extending throughout pregnancy, increase UCP1 expression in both sheep (6) and rats (25). Reduction in UCP1 when nutrition is restricted only in the late gestation may be an adaptation to conserve energy for the growth of other vital organs (6). Our study has demonstrated that UCP1 and expression of BAT-related genes are significantly reduced by maternal nutrition restriction in this period of maximal fetal growth. These changes occur in the absence of an effect on birth weight, a finding that is in concordance with other studies using a similar degree of maternal nutrient restriction $(26,27)$. These changes in BAT-related proteins and genes signify that subtle, but vital, changes in adipose tissue development can occur even when body weight is not obviously affected.

BAT has recently been shown to be present in pericardial adipose tissue of human adults (13). The function of BAT around the heart in mammals is unclear, although it has been suggested that it may serve to protect the myocardium from severe hypothermia, which can precipitate potentially fatal arrhythmias (13), have paracrine effects on cardiovascular function (28) and act as a plasma lipid-clearing organ protecting the heart from hypertriglyceridemia (10). Although BAT development in pericardial adipose tissue of newborns is effected by maternal nutrition in late gestation, these changes do not persist as the animal grows and are not accompanied by the alteration of genes predominantly expressed in WAT, indicating that the effect may be restricted to the newborn period. However, alteration of pericardial adipose tissue in older animals and humans and any long-term outcomes remain to be investigated.

In summary, pericardial adipose tissue is a depot of BAT in newborn sheep, which is nutritionally regulated. The depot changes from predominantly BAT to WAT in the newborn period. Maternal nutrient restriction in late gestation reduces the abundance of UCP1 and downregulates other BAT-related genes. Importantly, this nutritional intervention reduces the expression of $\beta 3 \mathrm{ADR}$ and $\mathrm{DIO} 2$, which are key regulators of brown adipocyte development and nonshivering thermogenesis. BAT is present in the adipose tissue depots around the heart in human adults and we have shown that its development in early life is a target of nutritional programming.

\section{METHODS}

\section{Animals and Diet}

Seventeen twin-bearing Border Leicester cross Swaledale sheep of similar age, body weight, and fat distribution with a known mating date were group housed and fed to fully meet their total metabolic requirements. At $110 \mathrm{~d}$ gestation, each was individually housed and 
randomly assigned to a nutrition group. Eight mothers were fed and consumed $100 \%$ of total metabolizable energy requirements for maternal body weight and stage of pregnancy, whereas the remaining nine were NR and fed with $60 \%$ of total metabolizable energy requirements until term. The diet comprised chopped hay and concentrates and was provided in a 3:1 ratio, as previously described (8). All animals had continual access to minerals, thus ensuring adequate intake of all vitamins and minerals regardless of nutrition group. All mothers delivered twins naturally at term. Colonic temperatures were recorded from each lamb around the time of birth and all remained normothermic (i.e., between 39 and $40{ }^{\circ} \mathrm{C}$ ).

One offspring was randomly selected for tissue sampling within $12 \mathrm{~h}$ of birth (day 0 ) following humane euthanasia by intravenous injection of barbiturate $(200 \mathrm{mg} / \mathrm{kg}$ pentobarbital sodium; Euthatal; RMB Animal Health, UK). Subsequently, each mother reared a single lamb until it was $30 \mathrm{~d}$ old, during which time mothers were fed hay ad libitum and up to $1 \mathrm{~kg}$ of concentrate throughout lactation. This procedure has no differential effect on the growth of the remaining twin (7) or maternal milk production (29), and the second lamb was tissue sampled at $30 \mathrm{~d}$ postnatal age (day 30 ) following euthanasia (as above). At tissue sampling, pericardial adipose tissue was immediately dissected, placed in liquid nitrogen, and stored at $-80{ }^{\circ} \mathrm{C}$ until further analysis. All operative procedures and experimental protocols had the required Home Office approval as designated by the UK Animals (Scientific Procedures) Act (1986).

\section{Laboratory Procedures}

mRNA detection. Total RNA was extracted from $500 \mathrm{mg}$ of pericardial adipose tissue using Tri-Reagent (Sigma Chemical Co, Poole, UK) followed by purification with an RNeasy Plus kit (Qiagen, West Sussex, UK). To verify the quantity and quality of total RNA extracted, spectrophotometric analysis (Nanodrop; Thermo Scientific, Wilmington, DE) was performed. For each sample, $2 \mu \mathrm{g}$ of RNA was reverse transcribed (RT) using reverse transcriptase and a Touchgene thermocycler (Techne; Barloworld Scientific, Stone UK). cDNA was synthesized from $2 \mu \mathrm{g}$ of RNA by reverse transcription in accordance with the manufacturer's protocol (High Capacity RNAto-cDNA kit, Applied Biosystems, Warrington, UK). For each RT analysis, appropriate negative controls were included to ensure there was no genomic DNA contamination. All cDNA was stored at -20 ${ }^{\circ} \mathrm{C}$ until further analysis.

For each gene, a standard curve was generated to ensure uniformity, efficiency, and accuracy for each 96-well plate. DNA for the standard curve was made after DNA extraction (QIA quick gel extraction kit 28704; Quigen, Crawley, UK) of the final product of PCR and run with $2 \%$ agarose gel electrophoresis. In addition, correct product validation of all primers was confirmed by product size on gel electrophoresis and, when necessary, gene sequencing was performed with the results checked against known sequences on the GenBank Database (30).

To establish mRNA abundance, qPCR was performed using a $10-\mu l$ reaction consisting of $3 \mu \mathrm{l}$ of cDNA, $5 \mu \mathrm{l}$ of Fast SYBR Green Master Mix (Applied Biosystems), and $1 \mu \mathrm{l}$ of forward and reverse ovine-specific oligonucleotide primers (Sigma-Aldrich, Gillingham, UK). The primer sequences are given in Table 2. The samples were run in duplicate and included a negative control and 10 -fold dilution standard curve for standardization. qPCR was performed using the Step One Plus real-time PCR thermocycler (Applied Biosystems). Results were excluded and experimental analysis was repeated if the standard curve analysis demonstrated an efficiency of $<90 \%$. Data were analyzed using $18 \mathrm{~S}$ mRNA as a housekeeping gene for the normalization of mRNA expression and the $2^{-\Delta C t}$ method and expressed as a ratio of the mean gene expression of day 0 control animals (31).

\section{Protein Analysis}

Mitochondria were prepared from $1 \mathrm{~g}$ of pericardial adipose tissue from each animal as previously described (32) and protein content was determined by bicinchoninic acid assay (33). The abundances of UCP1, VDAC, and cytochrome $c$ were determined by western blotting using UCP1 and VDAC antibodies as previously described (8) and cytochrome $c$ antibody ((H-104); SC-7159 (Santa Cruz Biotechnology, Santa Cruz, CA)) at a dilution of 1 to 1,000 . Specificity of the detection was confirmed using nonimmune rabbit serum and a range of molecular-weight markers was included on all gels. Densitometry analysis was performed on all membranes following image detection using a Fujifilm LAS-1000 cooled CCD camera (Fuji Photo Film, Tokyo, Japan) and results were expressed in arbitrary units. All gels were run in duplicate and a reference sample and negative control (from either hepatic or adipose tissue of the same 6-h-old control lamb) was included on each gel to allow comparison between groups. The membrane was exposed in a CCD camera (Fuji Luminescent Image Analyser LAS-1000; Fuji Film, Tokyo, Japan). Densitometry was performed on the visualized bands using Aida software (Aida Image Analyzer version 4.15.025, Raytest Isotopenmessgeräte $\mathrm{GmbH}$, Straubenhardt, Germany) to determine the relative abundance of the proteins studied. Data were analyzed following densitometry and expressed as a ratio of the mean gene expression of day 0 control animals.

\section{Statistical Analysis}

All data are presented as means \pm SEM and statistical significance was set at $P<0.05$. Data were assessed for normality using the Kolmogorov-Smirnov test followed by appropriate parametric or nonparametric analyses. An independent Student's test or MannWhitney test was used to assess both the effect of age and the maternal diet as appropriate. All data were analyzed using PASW software (version 17; IBM, Chicago, IL).

Table 2. Ovine-specific oligonucleotide forward and reverse primers used for real-time PCR

\begin{tabular}{|c|c|}
\hline Gene & Primer sequence \\
\hline \multirow[t]{2}{*}{ UCP1 } & Forward: 5'-AGA GGT GGT CAA GGT CAG \\
\hline & Reverse: 5'-ATT CTG TAA GCA TTG TAA GTC C \\
\hline \multirow[t]{2}{*}{$18 \mathrm{~S}$} & Forward: 5'-GTA ACC CGTTGA ACC CCA TT \\
\hline & Reverse: 5'-CAA GCTTAT GAC CCG CACTT \\
\hline \multirow[t]{2}{*}{$\mathrm{DIO} 2$} & Forward: AGCCGCTCCAAGTCCACTC \\
\hline & Reverse:TTCCACTGGTGTCACCTCCT \\
\hline \multirow[t]{2}{*}{$\beta 1 A D R$} & Forward: CGCTCA CCA ACC TCTTCA TC \\
\hline & Reverse: CAC ACA GGCTCT CAATGC TG \\
\hline \multirow[t]{2}{*}{$\beta 2 A D R$} & Forward: ATT GCC TCC TCC ATT GTG TC \\
\hline & Reverse: CAT CCT GCT CCA CTT GAC TG \\
\hline \multirow[t]{2}{*}{$\beta 3 A D R$} & Forward: CGCCTCCAACATGCCCTAC \\
\hline & Reverse: GCGTAGACGAAGAGCATCAC \\
\hline PGC1 $\alpha$ & $\begin{array}{l}\text { 5'-GTG TGT GTT TGC CTG GTTTG (from Primer } \\
\text { Design, Southampton, UK) }\end{array}$ \\
\hline \multirow[t]{2}{*}{ TGM2 } & Forward: 5'-TTT CAT GCT GGG TCA GTT CA \\
\hline & Reverse: 5'-AAC TTG GGG GTT GAC ATC CAG \\
\hline \multirow[t]{2}{*}{ KCNK3 } & Forward: 5'-CCTTCT ACTTCG CCA TCA CC \\
\hline & Reverse: 5'-GTG CAG CAG GTA CTT CAC GA \\
\hline \multirow[t]{2}{*}{ BMP7 } & Forward: 5'-GTC CCA AGA CGC CCA AGA AC \\
\hline & Reverse: 5'-TGC CTC TGG TCG CTG CTG \\
\hline \multirow[t]{2}{*}{ ADRP } & Forward: CAG AGA AGG GCA TGA AGA CC \\
\hline & Reverse:TCTTTT GCC CCA GTC ATA GC \\
\hline \multirow[t]{2}{*}{ Leptin } & Forward: CCA GGA TGA CAC CAA AAC C \\
\hline & Reverse:TGG ACA AACTCA GGA GAG G \\
\hline \multirow[t]{2}{*}{ Prolactin receptor } & Forward: 5'-CTC CAC CCA CCA TGA CTG AT \\
\hline & Reverse: 5'-CAG CGA ATC TGC ACA AGG TA \\
\hline
\end{tabular}




\section{ACKNOWLEDGMENTS}

The authors thank Mark Pope and Victoria Wilson for their help with laboratory techniques.

\section{STATEMENT OF FINANCIAL SUPPORT}

This work was supported by the European Union Sixth FrameworkProgramme for Research and Technical Development of the European Community-The Early Nutrition Programming Project (FOOD-CT-2005-007036) and by the Nottingham University Hospital's Charity.

Disclosure: The authors have no conflicts of interest to disclose.

\section{REFERENCES}

1. Power GG. Biology of temperature: the mammalian fetus. J Dev Physiol 1989;12:295-304.

2. Seale P, Lazar MA. Brown fat in humans: turning up the heat on obesity. Diabetes 2009;58:1482-4.

3. Symonds ME, Mostyn A, Pearce S, Budge H, Stephenson T. Endocrine and nutritional regulation of fetal adipose tissue development. J Endocrinol 2003;179:293-9.

4. Clarke L, Bryant MJ, Lomax MA, Symonds ME. Maternal manipulation of brown adipose tissue and liver development in the ovine fetus during late gestation. Br J Nutr 1997;77:871-83.

5. Finn D, Lomax MA, Trayhurn P. An immunohistochemical and in situ hybridisation study of the postnatal development of uncoupling protein-1 and uncoupling protein-1 mRNA in lamb perirenal adipose tissue. Cell Tissue Res 1998;294:461-6.

6. Budge H, Edwards LJ, McMillen IC, et al. Nutritional manipulation of fetal adipose tissue deposition and uncoupling protein 1 messenger RNA abundance in the sheep: differential effects of timing and duration. Biol Reprod 2004;71:359-65.

7. Budge H, Dandrea J, Mostyn A, et al. Differential effects of fetal number and maternal nutrition in late gestation on prolactin receptor abundance and adipose tissue development in the neonatal lamb. Pediatr Res 2003;53:302-8.

8. Mostyn A, Wilson V, Dandrea J, et al. Ontogeny and nutritional manipulation of mitochondrial protein abundance in adipose tissue and the lungs of postnatal sheep. Br J Nutr 2003;90:323-8.

9. Svensson PA, Jernås M, Sjöholm K, et al. Gene expression in human brown adipose tissue. Int J Mol Med 2011;27:227-32.

10. Festuccia WT, Blanchard PG, Deshaies Y. Control of Brown Adipose Tissue Glucose and Lipid Metabolism by PPAR? Front Endocrinol (Lausanne) 2011;2:84.

11. Puigserver P, Wu Z, Park CW, Graves R, Wright M, Spiegelman BM. A cold-inducible coactivator of nuclear receptors linked to adaptive thermogenesis. Cell 1998;92:829-39.

12. Bianco AC, Silva JE. Intracellular conversion of thyroxine to triiodothyronine is required for the optimal thermogenic function of brown adipose tissue. J Clin Invest 1987;79:295-300.

13. Sacks HS, Fain JN, Holman B, et al. Uncoupling protein-1 and related messenger ribonucleic acids in human epicardial and other adipose tissues: epicardial fat functioning as brown fat. J Clin Endocrinol Metab 2009;94:3611-5.

14. Bordicchia M, Liu D, Amri EZ, et al. Cardiac natriuretic peptides act via p38 MAPK to induce the brown fat thermogenic program in mouse and human adipocytes. J Clin Invest 2012;122:1022-36.
15. Festuccia WT, Blanchard PG, Turcotte V, et al. The PPARgamma agonist rosiglitazone enhances rat brown adipose tissue lipogenesis from glucose without altering glucose uptake. Am J Physiol Regul Integr Comp Physiol 2009;296:R1327-35.

16. Anflous K, Armstrong DD, Craigen WJ. Altered mitochondrial sensitivity for ADP and maintenance of creatine-stimulated respiration in oxidative striated muscles from VDAC1-deficient mice. J Biol Chem 2001;276:195460.

17. Cannon B, Nedergaard J. Brown adipose tissue: function and physiological significance. Physiol Rev 2004;84:277-359.

18. de Jesus LA, Carvalho SD, Ribeiro MO, et al. The type 2 iodothyronine deiodinase is essential for adaptive thermogenesis in brown adipose tissue. J Clin Invest 2001;108:1379-85.

19. Klingenspor M, Ivemeyer M, Wiesinger H, Haas K, Heldmaier G, Wiesner RJ. Biogenesis of thermogenic mitochondria in brown adipose tissue of Djungarian hamsters during cold adaptation. Biochem J 1996;316 (Pt 2):607-13.

20. Lin J, Handschin C, Spiegelman BM. Metabolic control through the PGC-1 family of transcription coactivators. Cell Metab 2005;1:361-70.

21. van Marken Lichtenbelt WD, Vanhommerig JW, Smulders NM, et al. Cold-activated brown adipose tissue in healthy men. $\mathrm{N}$ Engl J Med 2009;360:1500-8.

22. Lee P, Swarbrick MM, Zhao JT, Ho KK. Inducible brown adipogenesis of supraclavicular fat in adult humans. Endocrinology 2011;152:3597-602.

23. Roseboom TJ, van der Meulen JH, Ravelli AC, Osmond C, Barker DJ, Bleker OP. Effects of prenatal exposure to the Dutch famine on adult disease in later life: an overview. Mol Cell Endocrinol 2001;185:93-8.

24. Kind KL, Roberts CT, Sohlstrom AI, et al. Chronic maternal feed restriction impairs growth but increases adiposity of the fetal guinea pig. Am J Physiol Regul Integr Comp Physiol 2005;288:R119-26.

25. Souza TLV, Coelho CT, Guimaraes PB, et al. Intrauterine food restriction alters the expression of uncoupling proteins in brown adipose tissue of rat newborns. J Therm Biol 2012;37:138-43.

26. Edwards LJ, McMillen IC. Maternal undernutrition increases arterial blood pressure in the sheep fetus during late gestation. J Physiol (Lond) 2001;533(Pt 2):561-70.

27. Yuen BS, Owens PC, McFarlane JR, et al. Circulating leptin concentrations are positively related to leptin messenger RNA expression in the adipose tissue of fetal sheep in the pregnant ewe fed at or below maintenance energy requirements during late gestation. Biol Reprod 2002;67:911-6.

28. Ding J, Hsu FC, Harris TB, et al. The association of pericardial fat with incident coronary heart disease: the Multi-Ethnic Study of Atherosclerosis (MESA). Am J Clin Nutr 2009;90:499-504.

29. Gardner DS, Tingey K, Van Bon BW, et al. Programming of glucose-insulin metabolism in adult sheep after maternal undernutrition. Am J Physiol Regul Integr Comp Physiol 2005;289:R947-54.

30. Benson DA, Karsch-Mizrachi I, Lipman DJ, Ostell J, Sayers EW. GenBank. Nucleic Acids Res 2011;39(Database issue):D32-7.

31. Livak KJ, Schmittgen TD. Analysis of relative gene expression data using real-time quantitative PCR and the 2(-Delta Delta C(T)) Method. Methods 2001;25:402-8.

32. Symonds ME, Bryant MJ, Clarke L, Darby CJ, Lomax MA. Effect of maternal cold exposure on brown adipose tissue and thermogenesis in the neonatal lamb. J Physiol (Lond) 1992;455:487-502.

33. Smith PK, Krohn RI, Hermanson GT, et al. Measurement of protein using bicinchoninic acid. Anal Biochem 1985;150:76-85. 